\section{Sex Selection: Morality, Harm, and the Law}

Edgar Dahl, PhD

For centuries, couples have tried to choose the sex of their children. Italian men bit their wife's left ears during intercourse to beget daughters; Swedish men hung their pants on the right bedpost to father boys; while German woodcutters took their axes to bed and chanted: "Ruck, ruck, roy, you shall have a boy!" or "Ruck, ruck, raid, you shall have a maid!"

Sex selection is now a reality. Thanks to MicroSort ${ }^{\circledR}$, a new technology currently being tested in an FDA-approved clinical trial, parents will soon be able to choose the sex of their children before conception. MicroSort ${ }^{\circledR}$ permits the separation of those sperm that would produce a boy from those that would produce a girl. The separated sperm can then be used for artificial insemination. Given that not every attempt at artificial insemination results in a pregnancy, couples will have to undergo an average of three to five cycles of insemination, with each attempt costing about $\$ 2,500$. All expenses incurred must be covered by the couple undergoing treatment.

It will probably take another two or three years until the safety and efficacy of MicroSort ${ }^{\circledR}$ is established. Given the current results - at $3.4 \%$, the incidence of congenital malformations in babies conceived after MicroSort ${ }^{\mathbb{B}}$ is similar to that in the general population - there is virtually no doubt that the technology will get the approval of the FDA. If so, fertility centers around the globe may apply for a sublicensee to use MicroSort ${ }^{\circledR}$ and to offer preconception sex selection.

Scientific interest in the development of MicroSort ${ }^{\mathbb{R}}$ first arose from the desire to prevent X-linked genetic disorders. There are more than 500 sex-linked diseases, including hemophilia, Duchenne's muscular dystrophy, Lesch-Nyhan syndrome and Tay-Sachs disease. In most cases, the X-linked disorders are only expressed in the male offspring of carrier mothers. Thus, women who are carriers of a severe sex-linked disease often choose to have no children at all or to terminate their pregnancy if prenatal testing reveals the fetus to be a boy. MicroSort ${ }^{\mathbb{B}}$ will allow for the exclusive conception of unaffected girls.

Sex selection for the prevention of X-linked disorders is generally regarded as morally acceptable. The public debate, therefore, focuses almost entirely on sex selection for social

\footnotetext{
From the Centre for Dermatology and Andrology, Giessen, Germany.

Reprint requests to Edgar Dahl, PhD, Centre for Dermatology and Andrology, 14 Gaffky Street, Giessen, 35392, Germany. Email: Edgar.Dahl@ derma.med.uni-giessen.de

Copyright (C) 2007 by The Southern Medical Association

0038-4348/0-2000/10000-0105
}

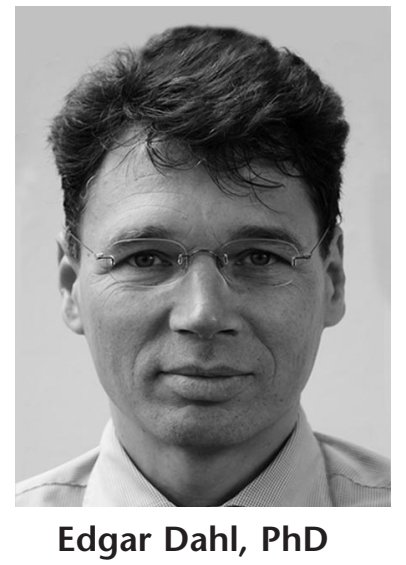

reasons. Many European countries, including Austria, Switzerland, Belgium, Italy, and Germany, have passed legislation that makes sex selection for any but the most serious of medical reasons a crime. For instance, Germany's notorious Embryo Protection Act of 1990 considers social sex selection a criminal offense punishable by imprisonment for one year. In Canada, the sentence is even harsher. According to the Assisted Human Reproduction Act of 2004, doctors performing sex selection for nonmedical reasons face up to ten years of imprisonment.

Is there any valid justification for criminalizing social sex selection and for sentencing a doctor to jail for, say, helping the parents of three boys to finally conceive a girl? I don't think so, at least not in a Western liberal democracy.

Modern Western societies are pluralistic societies. They consist of individuals devoted to differing religious views and, consequently, to differing moral views. Hence, in modern societies there will always be irresolvable differences over fundamental ethical issues. If a government tries to impose a particular morality upon its citizens, social conflict is inevitable. To avoid social tension and to deal with the moral pluralism of its citizens, the politics of modern societies ought to be based upon a "presumption in favor of liberty"; each citizen should have the right to live his life as he chooses so long as he does not infringe upon the rights of others. The state may interfere with the free choices of its citizens only to prevent serious harm to others.

The presumption in favor of liberty has three important implications. First, the burden of proof is always on those who opt for a legal prohibition of a particular action. It is they who must show that the action in question is going to harm others. Secondly, the evidence for the harm to occur has to be clear and persuasive. It must not be based upon highly speculative sociological or psychological assumptions. And finally, the mere fact that an action may be seen by some as contrary to their moral or religious beliefs does not suffice for a legal prohibition. The domain of the law is not the enforcement of morality, but rather the prevention of harm to others. With this in mind, let us turn to some of the most common 
objections to sex selection and see whether they provide a rational basis for outlawing it.

A constantly recurring objection to sex selection is that to choose the sex of our children is to "play God." This religious objection has been made to all kinds of medical innovations. For example, using chloroform to relieve the pain of childbirth was considered contrary to the will of God as it avoided the "primeval curse on woman." Since even fundamentalist Christians ceased to regard the alleviation of pain as morally impermissible, it is hard to take this objection seriously. What was once seen as "playing God" is now seen as acceptable medical practice. More importantly, the objection that sex selection is a violation of "God's Law" is an explicit religious claim. As most Western liberal democracies are based on a strict separation of state and church, no government is entitled to pass a law to enforce compliance with a specific religion. People who consider the option of sex selection as contrary to their religious beliefs are free to refrain from it, but they are not permitted to use the coercive powers of the law to impose their theology upon all those who do not share their religious world view.

Others are opposed to sex selection because they believe that it is somehow "unnatural." As with the objection that choosing the sex of our children is playing God, this claim most often expresses an intuitive reaction rather than a clearly reasoned moral response. That a particular human action is unnatural in no way implies that it is morally wrong. To transplant a kidney to save a human life is certainly unnatural, but is it for that reason immoral? Surely not! Thus, if we have to decide whether an action is morally right or wrong we cannot settle the issue by asking whether it is natural or unnatural.

Perhaps the most powerful objection to sex selection is that it may distort the natural sex ratio and lead to a socially disruptive imbalance of the sexes, as has occurred in countries such as India and China. However, whether a distortion of the natural sex ratio poses a real threat to Western societies is, of course, an empirical question that cannot be answered by mere intuition, but only by scientific evidence. According to representative social surveys, demographic research and data from gender clinics, couples in Western societies do not have a marked preference for either sex. What they are longing for is a family with children of both sexes. This distinct trend toward a "gender-balanced family" has not only been observed in the United States, but also in Canada, Great Britain, Italy, Spain, Sweden, Belgium, Germany, Austria, Switzerland, and The Netherlands.

Another frequently advanced objection claims that sex selection is sexist. Some feminist philosophers even have gone so far as to call it "the original sexist sin." This is preposterous! It is simply false that all people who would like to choose the sex of their children are motivated by the sexist belief that one sex is more valuable than the other. As evidenced by the data from gender clinics, almost all couples seeking sex selection are simply motivated by the desire to have at least one child of each sex. If this desire is based on any belief at all, it is based on the quite defensible assumption that raising a girl is different from raising a boy, but certainly not on the ridiculous idea that one sex is "superior" to the other.

Finally, there is the widely popular objection that sex selection will lead to the creation of "designer babies." Once we tolerate parents choosing the sex of their children, we are bound to tolerate parents choosing the intelligence, height, or even eye color of their children. However, this slippery slope argument is utterly untenable. It is perfectly possible to draw a legal line permitting some forms of selection and prohibiting others. Thus, if selection for sex is morally acceptable but selection for, say, intelligence is not, the former can be allowed and the latter not.

Given that sex selection does not harm anyone, there is no moral justification for a legal ban. 